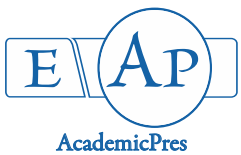

Preetha TS et al. (2021)

Notulae Scientia Biologicae

Volume 13, Issue 4, Article number 11024

DOI: $10.15835 / \mathrm{nsb} 13411024$

Research Article

\title{
Cryopreservation of aromatic ginger Kaempferia galanga L. by encapsulation-dehydration
}

\section{Thankappan S. PREETHA ${ }^{1 *}$, Achuthan S. HEMANTHAKUMAR ${ }^{2}$, Peringatulli N. KRISHNAN ${ }^{2}$}

\author{
${ }^{1}$ University of Kerala, Department of Botany, University College, Thiruvananthapuram 695034, Kerala, India; \\ preethahemanth@yahoo.com ("correspondingauthor) \\ ${ }^{2}$ University of Kerala, Biotechnology and Bioinformatics Division, Jawaharlal Nehru Tropical Botanic Garden and Research Institute, \\ Palode, Thiruvananthapuram695562,Kerala,India; ashemanthakumar@gmail.com;peringatulli@yahoo.co.uk
}

\begin{abstract}
Kaempferia galanga L. is an endangered multi-purpose medicinal plant in Family Zingiberaceae, the rhizomes of which are used for several ayurvedic formulations. Encapsulation-dehydration (ED) method was optimized for cryopreservation of shoot tips of $K$. galanga. Shoot tips (STS) bearing the apical meristem dissected from the established in vitro shoot cultures were preconditioned in MS+0.4 M sucrose prior to encapsulation in calcium alginate and the beads subsequently transferred to MS liquid+0.3 M sucrose for 3 days afterward dehydration inside the laminar airflow for 4 hours upon rapid freezing in $\mathrm{LN}$ and rapid thawing produced maximum $62.2 \%$ survival and $46.7 \%$ regeneration rates. Shoot regeneration was observed from the apical meristems exclusive of intermediary callus phase. The plantlets regenerated from cryopreserved STS transferred to the field were phenotypically analogous with the mother plant.
\end{abstract}

Keywords: cryopreservation; encapsulation-dehydration; Kaempferia galanga; monocot; preculture; shoot tips

Abbreviations: BA (6-benzyl adenine); GA 3 (giberellic acid); IAA (Indole 3-acetic acid); LN (liquid nitrogen); MS (Murashige and Skoog); NAA ( $\alpha$-naphthaleneacetic acid); STs (Shoot tips)

\section{Introduction}

Kaempferia galanga L., a high sought endangered multi-utility medicinal plant of the Family Zingiberaceae (Shirin et al., 2000) is cultivated in Tropical Asia for its aromatic rhizome which is having a wide range of medicinal applications (Sadiman, 1992). Various uses of aromatic ginger ( $K$ galanga) for health benefits, food and nutritional purposes are well documented (Preetha et al., 2016). Traditionally the rhizomes have been used to treat fever, amoebiasis, bruice, dandruff, headache, rheumatism, cholera, contusion, constipation, stomach ache, cold and chest pain (Limyati and Juniar, 1998; Kanjanapothi et al., 2004). The anticancer, antihypertensive, larvicidal (Choochote et al., 1999, Othman et al., 2002, Norjitet al., 2007), vasorelaxant (Othman et al., 2006), antioxidant (Sahoo et al., 2014), sedative (Ali et al., 2015) and antiinflammatory (Channabasavaiah et al., 2016) activities of the rhizome extract have been reported. The

Received: 10 Jul 2021. Received in revised form: 20 Sep 2021. Accepted: 18 Oct 2021. Published online: 02 Nov 2021.

From Volume 13, Issue 1, 2021, Notulae Scientia Biologicae journal uses article numbers in place of the traditional method of continuous pagination through the volume. The journal will continue to appear quarterly, as before, with four annual numbers. 
rhizomes contain a high value volatile oil, several alkaloids, starch, protein, aminoacids, minerals and fatty matter. The chemical components and biological activities of volatile oil have been worked out by Tewtrakul et al. (2005). The price of essential oil varies from US\$ 600-700 per $\mathrm{Kg}$ on the international market and is highly exploited by the local people and pharmaceutical industries (Chithra et al., 2005). More recently aromatic ginger was elevated to the status as a functional food (Srivastava et al., 2019). Conventional propagation of $K$. galanga is through clonal means via rhizomes, which remains dormant during drought and sprouting in spring. From the conservation point of view, the genetic resources of clonally propagated plants can be maintained as field collections, in green houses, in vitro or cryopreserved at ultralow temperatures of liquid nitrogen (FAO, 2013). During maintenance in the field, the plants were rendered to environmental pressures such as diseases, pests and extreme weather conditions (Rantala et al., 2019). To evade the troubles associated with conventional field maintenance, in vitro and cryopreservation techniques guarantee the longterm ex situ conservation and sustainable utilization of plant genetic resources. Among the in vitro strategies, cryopreservation is safe, cost-effective, long-standing method of plant germplasm preservation since during storage all metabolic activities are suspended thus ensuring high genetic stability together requiring minimum space for maintenance (Matsumoto, 2017). There is no need of regular subculturing in cryopreserved materials and the original germplasm can be stored for prolonged time periods with no change in their qualities (AlKhayri and Naik, 2017). Though in vitro plant regeneration systems are established well in $K$. galanga (Vincent et al., 1992; Shirin et al., 2000; Swapna et al., 2004; Rahman et al., 2005; Preetha et al., 2008, 2014; Mohanty et al., 2010; Senarat et al., 2017), so far there is only a single report on in vitro long-term conservation by cryopreservation using the PVS2 aided vitrification in this medicinal plant by us (Preetha et al., 2013) that recorded $30-40 \%$ recovery after cryopreservation. Since there is a critical necessity for realistic conservation endeavours to establish long-term germplasm collections of recalcitrant and tropical plants as because of the challenge and threat these species are facing (Mohd Noor et al., 2019), we here report the feasibility of cryopreserving shoot tips of $K$. galanga, using encapsulation-dehydration technique which offers a relatively high recovery rate (46.7\%) than the earlier established protocol and can be efficiently applied for producing synthetic seeds as well as ensuring the long-term conservation of the same with much more recovery in other economic Zingiberaceae species.

\section{Materials and Methods}

\section{Plant material}

In vitro shoot cultures of Kaempferia galanga L. established from rhizome segments were raised from explants collected from the natural habitat and maintained in the field gene bank of JNTBGRI campus (Herbarium voucher specimen TBG 60637). Shoot cultures were maintained in the proliferation medium, i.e., MS medium (Murashige and Skoog, 1962) fortified with $2.0 \mathrm{mgl}^{-1}$ 6-benzyl adenine (BA) (Sigma) and $0.5 \mathrm{mgl}$

${ }^{1} \alpha$-naphthaleneacetic acid (NAA) (Sigma) (Preetha, 2012). Subculturing was done after 4-6 weeks in culture bottles each with 3 shoots to enhance the production of strong, robust shoots. The cultures were incubated at $26 \pm 2{ }^{\circ} \mathrm{C}$ under 12 -hour photoperiod provided by cool white fluorescent tubes $\left(50-60 \mu \mathrm{molm}^{-2} \mathrm{~s}^{-1}\right)$ (Philips, India).

\section{Cryopreservation}

Preconditioning of STs on different sucrose concentrations at $25^{\circ} \mathrm{C}$ for $\mathrm{ED}$

$S T s$ from the vigorously growing in vitro shoot cultures were dissected under a dissection microscope (Kyowa, Tokyo) inside the laminar air flow chamber. The dissected $S T S(3 \mathrm{~mm})$ were cultured overnight at $26 \pm 2{ }^{\circ} \mathrm{C}$ in semisolid MS medium supplemented with $0.4 \mathrm{M}$ sucrose and incubated in the dark. 
Encapsulation of preconditioned STs

The sucrose-precultured $S T s$ were suspended in liquid MS medium free of calcium supplemented with $0.5 \mathrm{M}$ sucrose and $2.5 \%(\mathrm{w} / \mathrm{v})$ sodium alginate in $50 \mathrm{ml}$ sterile beakers. This mixture holding the $S T s$ was dispensed in to liquid MS medium containing $10 \%$ (w/v) sucrose and $100 \mathrm{mM} \mathrm{CaCl}_{2}$ (Merck) wherein they were left for 30 minutes to ensure polymerization.

\section{Preculture of encapsulated STs at $4{ }^{\circ} \mathrm{C}$}

The beads containing $S T s$ were then precultured at $4^{\circ} \mathrm{C}$ in liquid MS medium containing 0.3 or $0.5 \mathrm{M}$ sucrose ( $T 1$ and $T 2$ ) for 3 and 5 days ( $3 d$ and $5 d$ ) (i.e., the different treatments were denoted as $T 1(3 d), T 1(5 d)$, $T 2(3 d)$ and $T 2(5 d)$ respectively).

\section{Dehydration of precultured STs}

The precultured beads were dehydrated inside a laminar airflow chamber for $0-8 \mathrm{hrs}$ at $2 \mathrm{hrs}$ interval to determine the optimal dehydration duration. For each dehydration time, half of the beads were transferred to the recovery medium that served as the control and the other halves were placed in $1 \mathrm{ml}$ cryotubes (10 beads to a vial), which were immediately plunged in to LN. The beads of another control group that had received no sucrose preculture or dehydration treatment were similarly dealt with (the absolute control); half being cooled and the other half left uncooled.

Determination of moisture content (MC)

Total fresh weight of 25 beads with three replicates was measured after sucrose preculture and during the dehydration period (0-8 hrs). After each period of dehydration, the beads were oven dried at $130^{\circ} \mathrm{C}$ for 2 hrs to determine the dry weight. The MC was determined as:

$$
\% M C=\frac{\text { Fresh weight }- \text { Dry weight }}{\text { Fresh weight }} \times 100
$$

\section{Rewarming and recovery}

Rewarming of the cryopreserved $S T S$ were performed by rapidly immersing the cryotubes in a water bath at $40{ }^{\circ} \mathrm{C}$ for 30 seconds. Encapsulated non-cryopreserved (-LN) and encapsulated cryopreserved (+LN) STs were rehydrated for one night in MS+0.3 M sucrose, then transferred to MS medium supplemented with 0.5 $\mathrm{mgl}^{-1} \mathrm{BA}$ and $0.1 \mathrm{mgl}^{-1} \mathrm{GA}_{3}$ for 4 weeks and subsequently to $1.0 \mathrm{mgl}^{-1} \mathrm{BA}$ and $0.5 \mathrm{mgl}^{-1} \mathrm{NAA}$ recovery medium $(25 \mathrm{ml})$ in Petri dishes. The cultures were maintained at optimum culture conditions under dark for initial 10 days and then to standard conditions of illumination. Treated controls were processed in the same way except that they were not stored in LN.

\section{Viability and plant growth}

Stereomicroscopic (Nikon Eclipse) examination of the samples was performed regularly after plating on recovery medium. The $S T s$ were considered viable when they initiated growth and expanded. The survival levels were recorded based on the number of viable shoots out of the total number of thawed shoots. Shoot formation (recovery) was expressed as a percentage of the total number of shoots that proliferate normally after 4 weeks of transfer to recovery/ regrowth conditions.

The plants were maintained and multiplied under in vitro for up to two generations. The plantlets with 3-5 leaves and 2-3 roots weaned from the vessels were washed thoroughly in running tap water and transplanted in garden soil and river sand mixture (1:1) filled in polybags and hardened in a mist house under constant irrigation at $28 \pm 2{ }^{\circ} \mathrm{C}$ and $80 \pm 5 \% \mathrm{RH}(\mathrm{M} / \mathrm{s}$ Indo-American Exports Ltd.) for 1-2 weeks and then in a shade net house under 50\% sunlight and regular watering for 3-4 weeks. After hardening, the plantlets were transferred to the field and monitored. 


\section{Experimental design and statistical analysis}

Treatments were arranged in a completely randomized design (CRD). Each experiment consisted of ten meristems per treatment and was repeated thrice. Results were analysed by ANOVA and t-test. The means were separated according to the least significant difference (LSD) at $\mathrm{p} \leq 0.05$.

\section{Results}

The shoot meristems dissected out from in vitro shoot cultures were preconditioned in MS medium supplemented with $0.4 \mathrm{M}$ sucrose for one day and then used for cryopreservation experiments. A preliminary experiment conducted to see the effect of encapsulation without preculture on the regeneration of STS exhibited $95-100 \%$ survival rate and subsequent shoot regeneration after 3 days. Results on shoot tip cryopreservation in $K$. galanga through Encapsulation-dehydration indicated significant effects of three significant parameters such as (i) sucrose concentration during preculture, (ii) duration of preculture, (iii) duration of dehydration and their interaction.

\section{Effect of sucrose preculture on recovery of encapsulated and cryopreserved STs}

The effect of preculture in two different concentrations of sucrose $(0.3$ and $0.5 \mathrm{M})$ on shoot recovery after cryopreservation was studied. The best results in terms of shoot recovery (around 50\%) were obtained by preculturing with $0.3 \mathrm{M}$ sucrose for 3 days [ $T 1(3 d)]$ together with 4 hrs of dehydration (Table 1). Maximum $62.2 \%$ survival and $46.7 \%$ regeneration were observed in cryopreserved $S T s$ in $\mathrm{T} 1$ (3d) (Table 1). However, preculture in $0.3 \mathrm{M}$ sucrose for 5 days $[T 1(5 d)]$ reduced the survival and regeneration frequencies (Table 2). Also, an increase in the concentration of sucrose in the preculture medium from 0.3 to $0.5 \mathrm{M}$ sucrose significantly reduced the survival and regeneration of cryopreserved $S T$ s to around $20-30 \%$ and $10-20 \%$ correspondingly and it recorded maximum $25.6 \%$ survival and $16.7 \%$ regeneration frequencies (Tables 3 and 4).

Table 1. Recovery of $K$. galanga $S T$ s subjected to cryopreservation using encapsulation-dehydration after preculture of beads in MS+0.3 M sucrose for 3 days [T1(3d)]

\begin{tabular}{|c|c|c|c|c|c|}
\hline \multirow{2}{*}{$\begin{array}{c}\text { Dehydration } \\
\text { period (hrs) }\end{array}$} & \multirow{2}{*}{$\begin{array}{c}\text { \% Moisture } \\
\text { content }\end{array}$} & \multicolumn{2}{|c|}{ \% Survival } & \multicolumn{2}{c|}{ \% Regeneration } \\
\cline { 3 - 5 } & 86.15 & $-\mathrm{LN}$ & $+\mathrm{LN}$ & -LN & $+\mathrm{LN}$ \\
\hline 0 & 74.21 & $96.7 \pm 1.8^{\mathrm{a}}$ & $0.0 \pm 0.0$ & $90.0 \pm 1.8^{\mathrm{a}}$ & $0.0 \pm 0.0$ \\
\hline 2 & 29.25 & $76.7 \pm 1.8^{\mathrm{c}}$ & $56.7 \pm 1.8^{\mathrm{a}}$ & $60.0 \pm 0.0^{\mathrm{b}}$ & $0.0 \pm 0.0$ \\
\hline 4 & 20.09 & $50.0 \pm 3.1^{\mathrm{d}}$ & $46.7 \pm 1.8^{\mathrm{c}}$ & $40.0 \pm 3.2^{\mathrm{c}}$ & $36.7 \pm 1.8^{\mathrm{b}}$ \\
\hline 6 & 15.17 & $43.3 \pm 1.8^{\mathrm{e}}$ & $33.3 \pm 1.8^{\mathrm{d}}$ & $30.0 \pm 3.1^{\mathrm{d}}$ & $16.7 \pm 1.8^{\mathrm{c}}$ \\
\hline 8 & & &
\end{tabular}

*Values are mean \pm SE. Ten shoot tips were tested for each of three replications. Means followed by the same letter in the superscript in a column do not differ significantly based on ANOVA and LSD multiple ' $t$ ' test at $p \leq 0.05$.

Table 2. Recovery of $K$. galanga STs subjected to cryopreservation using encapsulation-dehydration after preculture of beads in MS+0.3 M sucrose for 5 days [T1(5d)]

\begin{tabular}{|c|c|c|c|c|c|}
\hline \multirow{2}{*}{$\begin{array}{c}\text { Dehydration } \\
\text { period (hrs) }\end{array}$} & \multirow{2}{*}{$\begin{array}{c}\text { \% Moisture } \\
\text { content }\end{array}$} & \multicolumn{2}{|c|}{ \% Survival } & \multicolumn{2}{c|}{ \% Regeneration } \\
\cline { 3 - 6 } & & $-\mathrm{LN}$ & $+\mathrm{LN}$ & $-\mathrm{LN}$ & +LN \\
\hline 0 & 85.14 & $80.0 \pm 3.1^{\mathrm{a}}$ & $0.0 \pm 0.0$ & $63.3 \pm 1.82^{\mathrm{a}}$ & $0.0 \pm 0.0$ \\
\hline 2 & 75.17 & $73.3 \pm 1.8^{\mathrm{a}}$ & $0.0 \pm 0.0$ & $60.0 \pm 3.16^{\mathrm{a}}$ & $0.0 \pm 0.0$ \\
\hline 4 & 51.61 & $66.7 \pm 1.8^{\mathrm{b}}$ & $36.7 \pm 1.8^{\mathrm{b}}$ & $60.0 \pm 0.0^{\mathrm{a}}$ & $30.0 \pm 3.1^{\mathrm{b}}$ \\
\hline 6 & 20.00 & $56.7 \pm 1.8^{\mathrm{c}}$ & $43.3 \pm 1.8^{\mathrm{a}}$ & $43.3 \pm 1.82^{\mathrm{b}}$ & $26.7 \pm 1.8^{\mathrm{a}}$ \\
\hline 8 & 17.15 & $36.7 \pm 1.8^{\mathrm{d}}$ & $33.3 \pm 1.8^{\mathrm{b}}$ & $30.0 \pm 0.00^{\mathrm{c}}$ & $20.0 \pm 3.2^{\mathrm{b}}$ \\
\hline
\end{tabular}

${ }^{*}$ Values are mean \pm SE. Ten shoot tips were tested for each of three replications. Means followed by the same letter in the superscript in a column do not differ significantly based on ANOVA and LSD multiple ' $t$ ' test at $p \leq 0.05$. 
Table 3. Recovery of $K$. galanga $S T$ s subjected to cryopreservation using encapsulation-dehydration after preculture of beads in MS+0.5 M sucrose for 3 days [T2(3d)]

\begin{tabular}{|c|c|c|c|c|c|}
\hline \multirow{2}{*}{$\begin{array}{c}\text { Dehydration } \\
\text { period (hrs) }\end{array}$} & \multirow{2}{*}{$\begin{array}{c}\text { \% Moisture } \\
\text { content }\end{array}$} & \multicolumn{2}{|c|}{ \% Survival } & \multicolumn{2}{c|}{ \% Regeneration } \\
\cline { 3 - 5 } & 84.39 & $-\mathrm{LN}$ & $+\mathrm{LN}$ & -LN & $+\mathrm{LN}$ \\
\hline 0 & 77.97 & $60.0 \pm 3.1^{\mathrm{a}}$ & $0.0 \pm 0.0$ & $66.7 \pm 3.7^{\mathrm{a}}$ & $0.0 \pm 0.0$ \\
\hline 2 & 54.30 & $50.0 \pm 3.8^{\mathrm{b}}$ & $0.0 \pm 0.0$ & $46.7 \pm 1.8^{\mathrm{b}}$ & $0.0 \pm 0.0$ \\
\hline 4 & 28.15 & $53.3 \pm 1.8^{\mathrm{b}}$ & $33.3 \pm 1.8^{\mathrm{a}}$ & $43.3 \pm 1.8^{\mathrm{b}}$ & $26.7 \pm 3.6^{\mathrm{a}}$ \\
\hline 6 & 18.66 & $40.0 \pm 3.1^{\mathrm{c}}$ & $26.7 \pm 1.8^{\mathrm{a}}$ & $40.0 \pm 0.0^{\mathrm{b}}$ & $16.7 \pm 3.6^{\mathrm{b}}$ \\
\hline 8 & & & $33.3 \pm 1.8^{\mathrm{c}}$ & $10.0 \pm 3.1^{\mathrm{b}}$ \\
\hline
\end{tabular}

${ }^{*}$ Values are mean \pm SE, ten shoot tips were tested for each of three replications. Means followed by the same letter in the superscript in a column do not differ significantly based on ANOVA and LSD multiple ' $t$ ' test at $p \leq 0.05$.

Table 4. Recovery of $K$. galanga $S T$ s subjected to cryopreservation using encapsulation-dehydration after preculture of beads in MS + 0.5 M sucrose for 5 days [T2(5d)]

\begin{tabular}{|c|c|c|c|c|c|}
\hline \multirow{2}{*}{$\begin{array}{c}\text { Dehydration } \\
\text { period (hrs) }\end{array}$} & \multirow{2}{*}{$\begin{array}{c}\text { \% Moisture } \\
\text { content }\end{array}$} & \multicolumn{2}{|c|}{ \% Survival } & \multicolumn{2}{c|}{ \% Regeneration } \\
\cline { 3 - 6 } & 77.22 & $76.7 \pm 1.8^{\mathrm{a}}$ & $0.0 \pm 0.0$ & $56.7 \pm 1.8^{\mathrm{a}}$ & $0.0 \pm 0.0$ \\
\hline 0 & 57.54 & $63.3 \pm 1.8^{\mathrm{b}}$ & $0.0 \pm 0.0$ & $43.3 \pm 1.8^{\mathrm{b}}$ & $0.0 \pm 0.0$ \\
\hline 2 & 21.62 & $50.0 \pm 3.1^{\mathrm{c}}$ & $20.0 \pm 3.1^{\mathrm{a}}$ & $36.7 \pm 3.6^{\mathrm{c}}$ & $16.7 \pm 1.8^{\mathrm{b}}$ \\
\hline 4 & 16.43 & $46.7 \pm 3.6^{\mathrm{d}}$ & $26.7 \pm 1.8^{\mathrm{a}}$ & $36.7 \pm 3.6^{\mathrm{c}}$ & $16.7 \pm 1.8^{\mathrm{a}}$ \\
\hline 6 & 12.65 & $43.3 \pm 1.8^{\mathrm{d}}$ & $20.0 \pm 0.0^{\mathrm{a}}$ & $30.0 \pm 0.0^{\mathrm{c}}$ & $10.0 \pm 1.8^{\mathrm{b}}$ \\
\hline 8 & &
\end{tabular}

${ }^{*}$ Values are mean \pm SE, ten shoot tips were tested for each of three replications. Means followed by the same letter in the superscript in a column do not differ significantly based on ANOVA and LSD multiple ' $t$ ' test at $p \leq 0.05$.

\section{Effect of preculture duration on recovery of encapsulated and cryopreserved STS}

To study the effect of preculture period on shoot tip survival after cryopreservation, preculture with 0.3 and $0.5 \mathrm{M}$ sucrose for 3 and 5 days followed by dehydration for $0-8 \mathrm{hrs}$ was assessed. Period of preculture greatly influenced the survival and regeneration of both desiccated (control) and frozen (treated) shoot tips. Higher survival rates $(60-70 \%)$ after cryopreservation were obtained in preculturing with $0.3 \mathrm{M}$ sucrose for 3 days [T1(3d)] (Table 1). Preculture with $0.3 \mathrm{M}$ sucrose for 5 days [T1(5d)] (Table 2) and $0.5 \mathrm{M}$ sucrose for 3 and 5 days $[T 2(3 d)$ and $T 2(5 d)$ respectively] (Tables 3 and 4 ) notably reduced the survival of the $S T s$ to around $30 \%$ after $\mathrm{LN}$ exposure.

\section{Effect of desiccation period on recovery of encapsulated and cryopreserved STS}

The survival and regeneration percentage of cryopreserved $K$. galanga $S T$ s also depended on the duration of dehydration. Encapsulated $S T s$ precultured in culture medium with 0.3 and $0.5 \mathrm{M}$ sucrose concentrations for 3 and 5 days and dehydrated afterwards at 0-8 hrs exhibited faster dehydration of the beads that have been precultured in lower concentrations of sucrose even for lesser dehydration duration. Longer dehydration period (6 hrs) was required to reduce the bead moisture content to optimum levels during preculture in higher concentrations of sucrose $(0.5 \mathrm{M})$. However, devoid of dehydration, no survival was obtained after exposure to LN. Preculture of the encapsulated $S T s$ in high sucrose medium reduced the moisture content of the beads from $95.69 \%$ (in absolute control) to $86.15 \%$ during the initial 3 days preculture in $0.3 \mathrm{M}$ sucrose [ $T 1(3 d)$ ] (Figure 1) which continued to decrease during dehydration reaching $29.25 \%, 15.17 \%$ and $12.25 \%$ after 4,6 and $8 \mathrm{hrs}$ of dehydration respectively. Desiccation beyond $6 \mathrm{hrs}$ resulted in drastic decline in the survival and regeneration of LN-exposed $S T S$ and desiccation controls in all the treatments. Highest regeneration percentages were recorded when the precultured encapsulated $S T S$ were dehydrated for 4-6 hrs in laminar airflow, resulting in a bead moisture content of 20-30\%. 


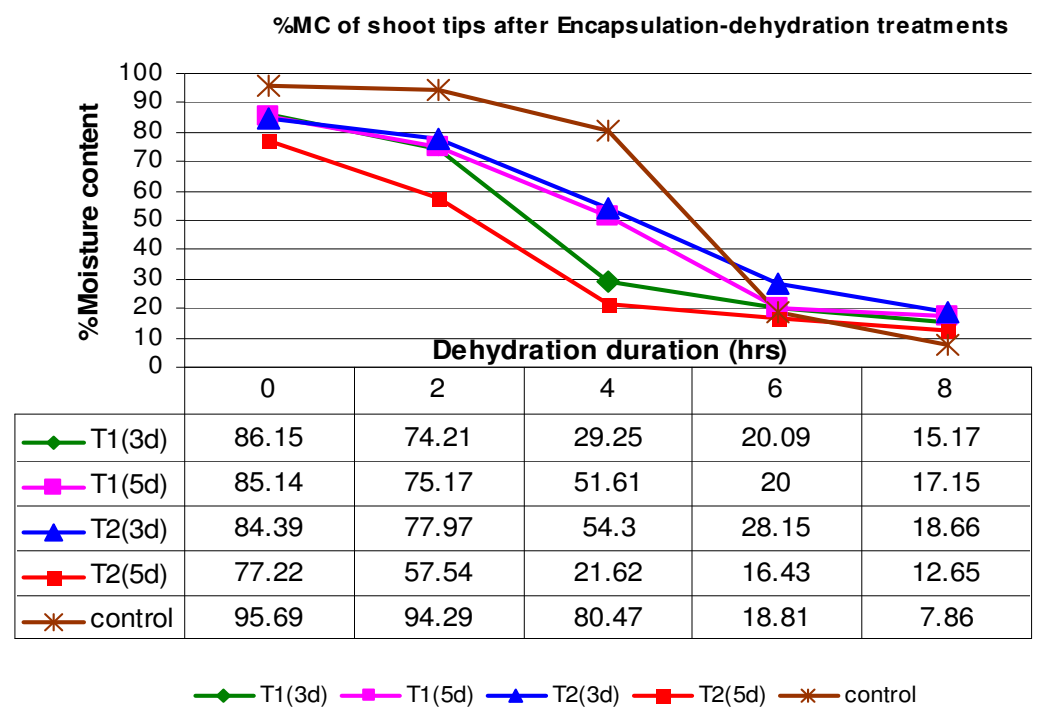

Figure 1 Moisture content (\%) of encapsulated $K$. galanga shoot tips subjected to $0-8$ hrs dehydration

\section{Effect of bead moisture content on recovery of encapsulated and cryopreserved STs}

The regrowth of both non-cryopreserved $(-\mathrm{LN})$ and cryopreserved $(+\mathrm{LN})$ shoots was greatly influenced by the water content of the precultured beads. For shoot tips desiccated to different $\mathrm{MC}$ ranging from $80-20 \%$ (control), very low percentage of survival was observed after cryopreservation. While in the absolute control, where no cryopreservation step was used, $95-100 \% S T s$ survived and regenerated. The initial water content of the control beads was high (95.69\%), which reduced to $86.15 \%$ by 3 days of preculture on $0.3 \mathrm{M}$ sucrose enriched medium, and to $15-20 \%$ by subsequent dehydration in the airflow chamber. Around $50 \%$ shoot recovery was obtained in this preculture treatment, together with 4-6 hours of dehydration, where moisture content was 29.25-20.09\% (Figure 1). In $K$. galanga, highest regeneration percentage (46.7\%) was noticed when the precultured encapsulated $S T S$ were dehydrated for 4 hrs, resulting in a bead moisture content of $29.25 \%$. Similarly, bead moisture content decreased to $84.39 \%$ after 3 -day preculture and to $77.22 \%$ after 5 -day preculture in $0.5 \mathrm{M}$ sucrose. Subsequent $6 \mathrm{hrs}$ desiccation period further reduced the moisture content to $28.15 \%$ and $16.43 \%$ respectively, thereby effecting $26.67-33.33 \%$ survival rates after cryopreservation (Figure 1).

\section{Shoot recovery}

Shoot recovery after LN exposure in $K$. galanga was proceeded through apical meristem regrowth (Figure 2b) with subsequent formation of leaf primordia (Figure 2c) followed by leaf expansion (Figure 2d). Shoot emergence occurred directly from the apical dome without callus development. Meristems which did not recover became dark brown or remained white when observed after 3-4 weeks of transfer to recovery medium. The shoots transferred to multiplication medium (MS+0.5 mgl-1 NAA+1.0 mgl- $\mathrm{BA}$ ), produced multiple shoots along with roots after 30 days (Figure 2e). The plantlets $(5-8 \mathrm{~cm})$ transferred to the field after short hardening phase were morphologically identical with the mother plants (Figure 2f). 

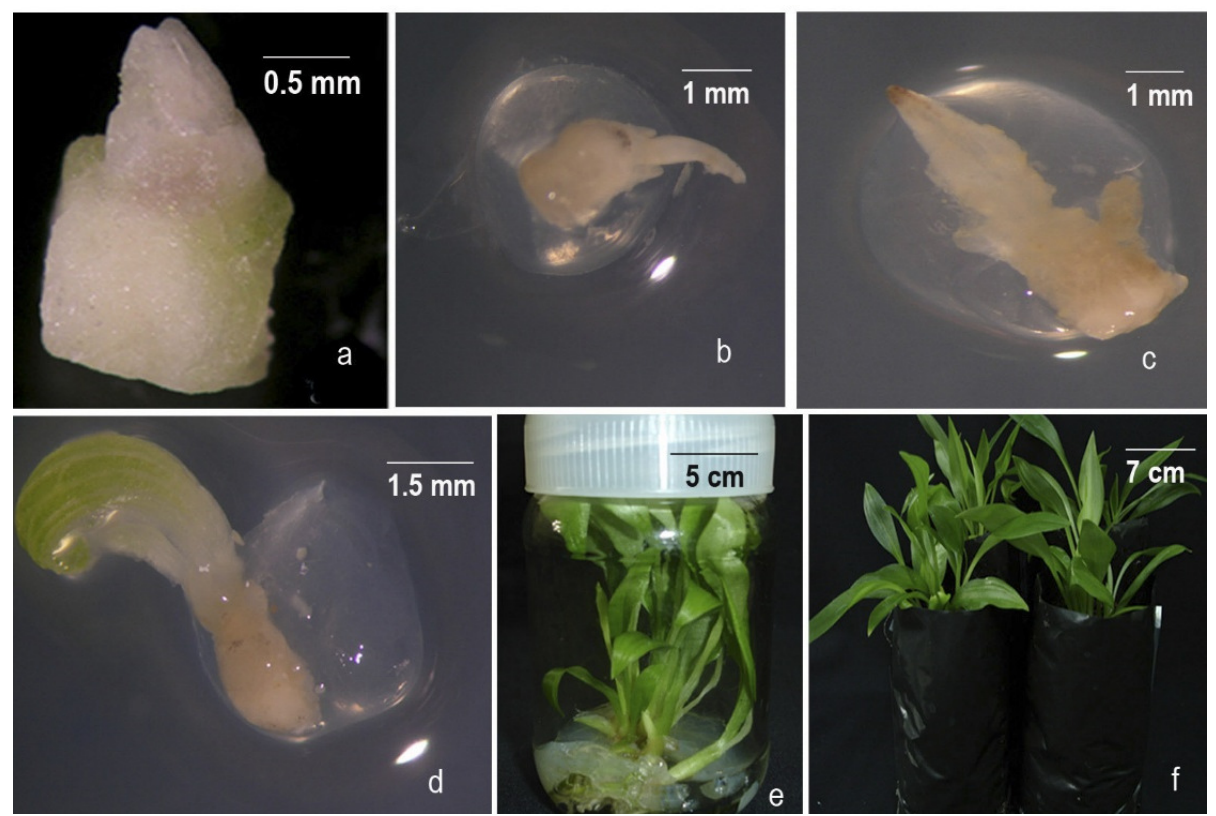

Figure 2. Shoot tip cryopreservation of $K$. galanga by encapsulation-dehydration

a Shoot tip $(3 \mathrm{~mm})$ selected for encapsulation; b\& c Stereomicroscopic view of shoot apical growth by breaking the encapsulation matrix in $\mathrm{LN}$-exposed shoot tips after 4 weeks of rewarming; $\mathbf{d}$ Initiation of shoot primordial growth after 8 weeks of rewarming; e Plantlet development in MS+0.5 $\mathrm{mgl}^{-1} \mathrm{NAA}+2.0 \mathrm{mgl}^{-1} \mathrm{BA} ; \mathbf{f}$ Hardened LN-recovered plantlets ready for field transfer.

The schematic representation of the protocol developed for shoot tip cryopreservation of $K$ galanga using Encapsulation-dehydration is:

Shoot tips ( $3 \mathrm{~mm})$ with 1-2 leaf primordia dissected from 1 month old plants

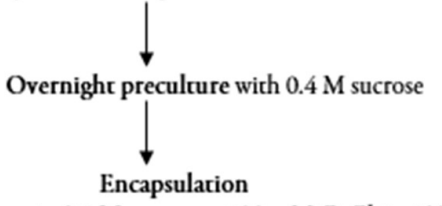

( $2.5 \%$ Sodium alginate in $0.5 \mathrm{M}$ sucrose $+100 \mathrm{mM} \mathrm{CaCl}_{2}$ in $10 \%$ sucrose)

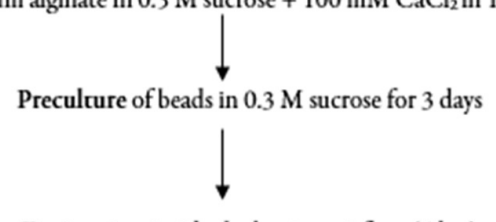

Desiccarion inside the laminar airflow ( $4 \mathrm{hrs})$

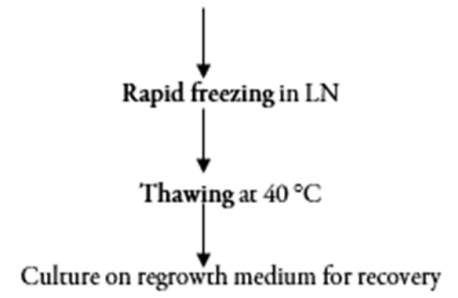

i. MS + 0.3 M sucrose medium (overnight)

i. $\mathrm{MS}+0.5 \mathrm{mgl}^{-1} \mathrm{BA}+0.1 \mathrm{mgl}^{-1} \mathrm{GA}_{3}$ (3 weeks)

ii. $\mathrm{MS}+1.0 \mathrm{mgl}^{-1} \mathrm{BA}+0.5 \mathrm{mgl}^{-1} \mathrm{NAA}$ (3-4 weeks)

Planders 


\section{Discussion}

Plant tissues have more than $70 \%$ water content in their cells and when these specimens were exposed to $-196^{\circ} \mathrm{C}$, the ultra low temperature of $\mathrm{LN}$, there is the chance of intra cellular ice crystal formation inside the cells, the greatest challenge in cryopreservation technique. These ice crystals formed during cooling in LN cause 'freezing injuries' such as rupture of cell membranes resulting in the loss of semi-permeability, cellular compartmentation and structural integrity leading to cell death (Oliveira et al. 2019). Hence the cellular water content needs to be optimized to prevent the intracellular crystallization, which can be achieved by inducing osmotic dehydration with the help of different cryoprotection treatments such as PVS2/ droplet vitrification, Encapsulation-dehydration, Encapsulation-vitrification, step-wise freezing, etc. Here, an efficient method was achieved using a procedure of encapsulation-dehydration for cryopreserving the shoot tip of $K$. galanga. Recently this method was suggested for the eradication of viruses from apple root stock (Bettoni et al., 2018). The technique was developed initially by Dereuddre et al. (1990) for cryopreservation of shoot tips and somatic embryos is based on the technology for producing synthetic seeds (Redenbaugh et al., 1986) and it combines two cryoprotective treatments, preculture with sucrose and air drying for inducing cytoplasmic vitrification; thereby avoiding the formation of intracellular ice crystals during subsequent rapid cooling in LN. In encapsulation-dehydration, the extraction of water from the shoot tips results from the progressive osmotic dehydration with the sucrose enriched medium followed by additional loss of water through evaporation from the beads (Fabre and Dereuddre, 1990). In the present study also, resistance to air dehydration and rapid cooling in LN was induced by overnight pretreatment of the excised shoot tips in MS medium supplemented with $0.4 \mathrm{M}$ sucrose and subsequent preculture of encapsulated shoot tips in high sucrose enriched medium. Preconditioning of the explant materials in medium enriched with osmotic agents like sucrose, mannitol/ sorbitol has increased the efficiency of cryopreservation in many taxa (San Jose et al., 2014; Zhang et al., 2017) as well as in the cryopreservation approach by vitrification in $K$. galanga itself (Preetha et al., 2013).

Experiments on cryopreservation by encapsulation-dehydration generally use sucrose as the cryoprotectant, which induces osmotic dehydration as well as contributing to the increased concentrations of sugar, starch and proline in the shoot tips, thus enhancing the stability of membranes under conditions of severe dehydration (Matsumoto and Sakai, 2003; Kaczmarczyket al., 2011). In K. galanga, the dissected STs were encapsulated using Sodium alginate solution having high sucrose concentration $(0.5 \mathrm{M})$ which was dropped in to liquid culture medium containing high concentration of $\mathrm{CaCl}_{2}(100 \mathrm{mM})$ and sucrose $(10 \%)$. Accordingly, the sucrose is absorbed by the explants, thereby increasing the concentration of internal solutes.

Preculture of the encapsulated $S T S$ again in high sucrose medium resulted in the accumulation of sugars in the alginate bead and tissues (Gonzales Arnao and Engelmann, 2006) which retained the viability of the tissue during dehydration treatment. Also, it reduced the MC of the explants through an osmotic effect. In contrast, Panta et al. (2014) found that sucrose pretreatment had no positive effect on survival rate in encapsulation dehydration technique of potato shoot tips. After preculturing with $0.3 \mathrm{M}$ sucrose for 3 days, $100 \%$ survival was obtained with encapsulated $K$. galanga STs that were not subjected to dehydration or LN freezing. Period of preculture greatly influenced the survival and regeneration of both $-\mathrm{LN}$ (control) and $+\mathrm{LN}$ (treated) STs. Very little of the LN-exposed shoot tips were survived and regenerated while the sucrose concentration as well as the pre-culture duration was increased. Better responses with respect to survival percentage and recovery rates were obtained by preculturing with $0.3 \mathrm{M}$ sucrose for 3 days [ $T 1(3 d)$ ] together with 4 hours of dehydration. Preculture for two more days in the same medium or high sucrose concentration $(0.5 \mathrm{M})$ caused a considerable decrease in shoot recovery, which might be due to the toxicity created during exposure to high sucrose concentrations.

Dehydration of the precultured beads to optimum moisture levels is extremely important to achieve

survival and regeneration of explants after cryopreservation as the desiccation step is removing a significant amount of crystallizable water from the shoot tissue facilitating their survival after cryopreservation. In $K$. galanga, no survival was observed when non-desiccated, precultured explants were frozen in LN. The survival 
and regeneration frequency of $\mathrm{LN}$-non-exposed shoot tips decreased with the increasing dehydration duration which completely agrees with the findings of Shatnawi (2011) in Capparis spinosa, where the shoot tips were exposed to similar treatments prior to cryopreservation. Samples need to withstand a moisture reduction to an optimum level to ensure no detrimental ice crystallization during LN treatment (Bachiri et al., 2001). The optimal duration of dehydration in this case was 4-6 hours by which time the MC in beads was 20-30\%. Bead MCs between 15-30\% are required for optimal survival after cryopreservation (Engelmann 1997), which was also the case in $K$. galanga. Highest regeneration percentage (46.7\%) was recorded when the precultured encapsulated $S T s$ were dehydrated for 4 hrs in laminar airflow, resulting in a bead moisture content of $29.25 \%$. In agreement with this, the encapsulated beads of Clitoria ternatea dehydrated for 4 hrs had $60 \%$ survival after freezing in LN, of which 65\% regrown after cryostorage (Nair et al., 2019). The results indicate that preculture duration, concentration of sucrose in the medium and optimal MC in the beads are critical factors for cryopreserving $K$. galanga $S T$ s.

Since only small tissue areas endure cryopreservation, it is necessary to apply plant growth regulators (PGRs) in to the regeneration medium to stimulate cell division and growth. Combinations of cytokinins and $\mathrm{GA}_{3}$ in the recovery medium appear to be more beneficial for plant growth and development after LN immersion in many species (Lee et al., 2011; Preetha et al., 2013) and here, shoot recovery was obtained in medium supplemented with $0.5 \mathrm{mgl}^{-1} \mathrm{BA}$ and $0.1 \mathrm{mgl}^{-1} \mathrm{GA}_{3}$. Transfer of the shoots to medium supplemented with $1.0 \mathrm{mgl}^{-1} \mathrm{BA}$ and $0.5 \mathrm{mgl}^{-1} \mathrm{NAA}$ promoted the production of plantlets indicating that altering PGR levels in the recovery medium has improved the survival and thereby stimulated direct regeneration of whole plantlets by meristematic dome development as observed in Dioscorea (Mandal and Ahuja-Ghosh, 2007). The LNrecovered plantlets after the short hardening phase got established in the field at high rate (80\%) and were free from morphological deformities.

\section{Conclusions}

The results projected here demonstrate the feasibility and utility of cryopreservation in long-term conservation approaches in $K$. galanga. The novel method of $K$. galanga shoot meristem cryopreservation by encapsulation-dehydration that recorded a much-improved recovery than the already established vitrification method holds promise for the long-term cryo-banking of this species. The morpho genetically uniform cryoregenerants also revealed consistent utilization of this economically important plant genetic resource. Furthermore, this procedure can be considered as a footstep for seed production of the same or allied species of zingiberaceaeous group according to its demand.

\section{Authors' Contributions}

TSP has designed, conducted the experiments and wrote the manuscript, ASH helped in the analysis of the results and checking the draft and PNK provided overall supervision of the work. All authors read and approved the final manuscript.

\section{Acknowledgements}

We are thankful to the Director, Jawaharlal Nehru Tropical Botanic Garden and Research Institute, Palode, Thiruvananthapuram, Kerala, India for providing the facilities. We acknowledge the financial assistance provided by Department of Biotechnology, Government of India as a part of 'National Gene Bank 
for Medicinal and Aromatic Plants project' and Council of Scientific and Industrial Research, Government of India for the Senior Research Fellowship to T. S. Preetha.

\section{Conflict of Interests}

The authors declare that there are no conflicts of interest related to this article.

\section{References}

Ali MS, Dash PR, Nasrin M (2015). Study of sedative activity of different extracts of Kaempferia galangal in Swiss albino mice. BMC Complement Alternative Medicine 15:158. https://doi.org/10.1186/s12906-015-0670-z

Al-Khayri JM, Naik PM (2017). Date palm micropropagation: advances and applications. Ciencia e Agrotecnologia 41(4):347-358. https://doi.org/10.1590/1413-70542017414000217

Bachiri Y, Song GQ, Plessis P, Shoar Ghaffri A, Rekad T, Morriset C (2001). Routine cryopreservation of kiwifruit (Actinidia spp) germplasm by encapsulation-dehydration: Importance of plant growth regulators. CryoLetters 22:61-74.

Bettoni JC, Costa MD, Souza JA, Volk GM, Nickel O, da Silva FN, Kretzschmar AA (2018). Cryotherapy by encapsulation-dehydration is effective for in vitro eradication of latent viruses from 'Marubakaido' apple root stock. Journal of Biotechnology 269:1-7. https://doi.org/10.1016/j.jbiotec.2018.01.014

Channabasavaiah JP, Parameswarappa LK, Jayesh M, Kutty NG (2016). Extraction, characterization and evaluation of Kaempferia galanga L. (Zingiberaceae) rhizome extracts against acute and chronic inflammation in rats. Journal of Ethnopharmacology 194:434-439. https://doi.org/10.1016/j.jep.2016.10.010

Chithra M, Martin KP, Sunandakumari C and Madhusoodanan PV (2005). Protocol for rapid propagation and to overcome delayed rhizome formation in field established in vitro derived plantlets of Kaempferia galanga $\mathrm{L}$. Scientia Horticulturea 104:113-120. https://doi.org/10.1016/jscienta.2004.08.014

Choochote W, Kanjanapothi D, Panthanga A, Taesotikul T, Jitpakdi A, Chaithong U, Pitasawat B (1999). Larvicidal, adulticidal and repellent effects of Kaempferia galanga. Southeast Asian Journal of Tropical Medicine and Public Health 30:470-476.

Dereuddre J, Scottez C, Arnaud Y, Duron M (1990). Resistance d'apex caulinaires de vitro plants de Poirier (Pyruscommunis L. cv. Beurre Hardy), enrobes dans endurcissement prealable au froid. Comptes Rendus Academie des Sciences Paris 310:317-323.

Engelmann F (1997). In: Biotechnology and plant genetic resources: Conservation and Use. Ford-Llyod BV, Newburry JH, Callow JA (Eds). CABI, Wellingford, pp 119-162.

Fabre J, Dereuddre J (1990). Encpsulation-Dehydration: A new approach to cryopreservation of Solanum shoot tips. CryoLetters 11:413-426.

FAO (2013). Gene bank standards for plant genetic resources for food and agriculture. Rome.

Gonzalez-Arnao MT, Engelmann F (2006). Cryopreservation of plant germplasm using the encapsulation-dehydration technique: review and case study on sugarcane. CryoLetters 27:155-168.

Kaczmerczyk A, Rokka VM, Keller J (2011). Potato shoot tip cryopreservation, a review. Potato Research 54:45-79.

Kanjanapothi D, Panthong A, Lertprasersuke N, Taesotikul T, Rujjanawate C, Kaewpinit D (2004). Toxicity of crude rhizome extract of Kaempferia galanga L. (PrhHom). Journal of Ethnopharmacology 90(2-3):359-365. https://doi.org/10.1016/j.jep.2003.10.020

Lee YG, Popova E, Cui HY, Kim HH, Park SU, Bae CH, Lee SC, Engelmann F (2011). Improved cryopreservation of chrysanthemum (Chrysanthemum morifolium) using droplet-vitrification. CryoLetters 32:486-497.

Limyati DA, Juniar BII (1998). Jamu Gendong, a kind of traditional medicine in Indonesia: the microbial contamination of its raw materials and end products. Journal of Ethnopharmacology 63(3):201-208. https://doi.org/10.1016/s0378-8741(98)00082-8

Mandal BB, Ahuja-Ghosh S (2007). Regeneration of Dioscorea floribunda plants from cryopreserved encapsulated shoot tips: Effect of plant growth regulators. CryoLetters 28:329-336. 
Matsumoto T (2017). Cryopreservation of plant genetic resources: Conventional and new methods. Reviews in Agricultural Science 5:13-20. https://doi.org/10.7831/ras.5.13

Matsumoto T, Sakai A (2003). Cryopreservation of axillary shoot tips of in vitro-grown grape (Vitis) by a two-step vitrification protocol. Euphytica 131(3):299-304. https://doi.org/10.1023/A:1024024909864

Mohanty S, Parida R, Singh S, Joshi RK, Subudhi E, Nayak S (2010). Biochemical and molecular profiling of micropropagated and conventionally grown Kaempferia galanga. Plant Cell Tissue and Organ Culture 106(1):39-46. https://doi.org/10.1007/s 11240-010-9891-5

Mohd Noor N, Sulong N, Reed BM (2019). Cryopreservation of shoot tips of recalcitrant and tropical species: Advances and strategies. Cryobiology 87:1-14. https://doi.org/10.1016/j.cryobiol.2019.01.008

Murashige T, Skoog F (1962). A revised medium for rapid growth and bio-assays with tobacco tissue cultures. PhysiologiaPlantarum15:473-497. https://doi.org/10.1111/j.1399-3054.1962.tb08052.x

Nair DS, Reghunath BR, Soni KB, Alex S (2019). Cryopreservation of encapsulated encapsulated axillary buds of Clitoria ternatea (L.). CryoLetters 40(1):28-35.

Norjit K, Laohakunjit N, Kerdchoechuen O (2007). Antibacterial effect of five Zingiberaceae essential oils. Molecules 12:2047-2060. https://doi.org/10.3390/12082047

Oliviera DV, Santos IRI, Martins IS, Salomao AN (2019). Cryopreservation of shoot tips of "Brazilian Ginseng” (Pfaffia glomerata (Spreng.) Pedersen) by vitrification. Journal of Agricultural Science 11:146-155.

Othman R, Ibrahim H, Ali MM, Mustafa MR, Awang K (2006). Bioassay guided isolation of a vaso relaxant active compound from Kaempferia galanga L. 13:61-66. https://doi.org/10.1016/j.phymed.2004.07.004.Epub 2005Jun 27

Othman R, Ibrahim H, Mohd MA, Awang K, Gilani AV, Musthafa MR (2002). Vaso relaxant effect of ethyl cinnamate isolated from Kaempferia galangal on smooth muscles of rat aorta. Planta Medica 68:655-657. https://doi.org/10.1055/s-2002-32900

Panta A, Panis B, Ynouye C, Swennen R, Roca W, Tay D, Ellis D (2014). Improved cryopreservation method for the longterm conservation of the world potato germplasm collection. Plant Cell Tissue and Organ Culture 120:117-125. https://doi.org/10.1007/s11240-014-0585-2

Preetha TS (2012) Studies on in vitro conservation of Kaempferia galanga L., PhD Thesis, University of Kerala.

Preetha TS, Hemanthakumar AS, Krishnan PN (2016). A comprehensive review of Kaempferia galanga L. (Zingiberaceae): A high sought medicinal plant in Tropical Asia. Journal of Medicinal Plant Studies 4:270-276.

Preetha TS, Hemanthakumar AS, Padmesh P, Krishnan PN (2014.) A high frequency micro-cloning protocol for subsequent cryopreservation in Kaempferia galanga L.: An endangered, over-exploited medicinal plant in pharmaceutics. IOSR Journal of Pharmacy 4(12):19-23.

Preetha TS, Hemanthkumar AS, Decruse SW, Krishnan PN, Seeni S (2008). Effect of synthetic auxins on somatic embryogenesis from in vitro - derived leaf base of Kaempferia galanga L. Phytomorphology 58:117-124.

Preetha TS, Hemanthkumar AS, Krishnan PN (2013). Shoot tip cryopreservation by vitrification in Kaempferia galanga L. An endangered overexploited medicinal plant in Tropical Asia. IOSR Journal of Pharmacy and Biological Sciences 8(3):19-23. https://doi.org/10.9790/3008-0831923

Rahman MM, Amin MN, Ahmed T, Ahmad S, Habib IA, Ahmed R, Ahmed MB (2005). In vitro rapid propagation of black thorn (Kaempferia galanga L.): A rare medicinal and aromatic plant of Bangladesh. Journal of Biological Sciences 5:300-304. https://doi.org/10.3923/jbs.2005.300.304

Rantala S, Kaseva J, Karhu S, Vetelainen M, Uosukainen M, Haggman H (2019). Cryopreservation of Ribes nigrum (L.) dormant buds: Recovery via in vitro culture to the field. Plant Cell Tissue and Organ Culture 138:109-119. https://doi.org/10.1007/s11240-019-01607-5

Redenbaugh K, Paasch BD, Nichol JW, Kessler ME, Viss PR, Walker KA (1986). Somatic seeds: encapsulation of asexual plant embryos. Biotechnology 4:797-801. https://doi.org/10.1038/nbt0986-797

Sadimann J (1992). Kentjur - A little known Asian Spice and medicinal plant (Kaempferia galanga L.). Pharmazie 47:636639.

Sahoo S, Parida R, Singh S, Padhy RN, Nayak (2014). Evaluation of yield, quality and antioxidant activity of essential oil of in vitro propagated Kaempferia galanga Linn. Journal of Acute Disease 201:124-130. https://doi.org/10.1016/S2221-6189(14)60028-7

San Jose MC, Valladares S, Vazquez -Janeiro L, Corredoira E (2014). Cryopreservation of in vitro grown shoot tips of Alnus glutinosa (L.) Gaertn. Acta Physiologia Plantarum 36:109-116. 
Senarath RMUS, Karunarathna BMAC, Senarath WTPSK, Jimmy GC (2017). In vitro propagation of Kaempferia galanga (Zingiberaceae) and composition of larvicidal activity and phytochemical identities of rhizomes of tissue cultured and naturally grown plants. Journal of Applied Biotechnology \& Bioengineering 2(4):00040. https://doi.org/ 10.15406/jabb.2017.02.00040

Shatnawi (2011). Cryopreservation of Capparis spinosa shoot tips via vitrification, encapsulation-dehydration and encapsulation-vitrification. World Applied Sciences Journal 15(3):318-325.

Shirin F, Kumar S, Mishra Y (2000). In vitro plantlet production system for Kaempferia galanga, a rare Indian medicinal herb. Plant Cell Tissue and Organ Culture 63:193-197. https://doi.org/10.1023/A:1010635920518

Srivastava N, Ranjana, Singh S, Gupta AC, Shanker K, Bawankula DU, Luqman S (2019). Aromatic ginger (Kaempferia galanga L.) extracts with ameliorative and protective potential as a functional food, beyond its flavor and nutritional benefits. Toxicology Reports 6:521-528. https://doi.org/10.1016/j.toxrep.2019.05.014

Swapna TS, Binitha M and Manju TS (2004). In vitro multiplication in Kaempferia galanga Linn. Applied Biochemistry and Biotechnology 118:233-241. https://doi.org/10.1385/ABAB:118:1-3:233

Tewtrakul S, Yuenyongsawad S, Kummee S, Latthya Atsawajaruwan L (2005). Chemical components and biological activities of volatile oil of Kaempferia galanga Linn. Songklanakarin Journal of Science and Technology 27:503507.

Vincent KA, Hariharan M, Mathew KM (1992). Embryogenesis and plantlet formation in tissue culture of Kaempferia galanga L. - a medicinal plant. Phytomorphology 42:253-256.

Zhang JM, Han L, Lu XX, Volk GM, Xin X, Yin GK, He JJ, Wang L, Chen XL (2017). Cryopreservation of Jerusalem artichoke cultivars using an improved droplet-vitrification method. Plant Cell Tissue and Organ Culture 128:577-587. https://doi.org/10.1007/s11240-016-1135-X

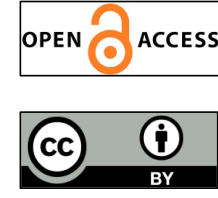

The journal offers free, immediate, and unrestricted access to peer-reviewed research and scholarly work. Users are allowed to read, download, copy, distribute, print, search, or link to the full texts of the articles, or use them for any other lawful purpose, without asking prior permission from the publisher or the author.

License - Articles published in Notulae Scientia Biologicae are Open-Access, distributed under the terms and conditions of the Creative Commons Attribution (CC BY 4.0) License.

(C) Articles by the authors; SHST, Cluj-Napoca, Romania. The journal allows the author(s) to hold the copyright/to retain publishing rights without restriction. 